\title{
(6) OPEN ACCESS \\ Impact of emergency physician experience on decision-making in patients with suspected community-acquired pneumonia and undergoing systematic thoracic CT scan
}

\author{
Josselin Le Bel, ${ }^{\oplus 1,2}$ Thierry Pelaccia, ${ }^{3,4}$ Patrick Ray, ${ }^{5}$ Charles Mayaud, ${ }^{6}$ \\ Anne-Laure Brun, ${ }^{7}$ Pierre Hausfater, ${ }^{8,9}$ Enrique Casalino, ${ }^{9}$ Mikhael Benjoar, ${ }^{7}$ \\ Yann-Erick Claessens, ${ }^{10}$ Xavier Duval, ${ }^{2,11}$ On behalf of the ESCAPED study group
}

Additional material is published online only. To view please visit the journal online (http://dx.doi.org/10.1136/ emermed-2018-207842).

For numbered affiliations see end of article.

\section{Correspondence to}

Dr Josselin Le Bel, Department of General Practice, Universite Paris Diderot UFR de Medecine Site Xavier-Bichat, Paris 75018, France;

josselin.lebel@univ-parisdiderot.fr

Y-EC and XD contributed equally.

Received 27 May 2018 Revised 5 May 2019 Accepted 17 May 2019 Published Online First 24 June 2019
Check for updates

(C) Author(s) (or their employer(s)) 2019. Re-use permitted under CC BY-NC. No commercial re-use. See rights and permissions. Published by BMJ.

To cite: Le Bel J, Pelaccia T, Ray $\mathrm{P}$, et al. Emerg Med J 2019:36:485-492.
ABSTRACT
Objectives To determine whether the impact of a thoracic CT scan on community-acquired pneumonia (CAP) diagnosis and patient management varies according to emergency physician's experience ( $\leq 10 \mathrm{vs}>10$ years).

Methods Early thoracic CT Scan for CommunityAcquired Pneumonia at the Emergency Department is an interventional study conducted from November 2011 to January 2013 in four French emergency departments, and included suspected patients with CAP. We analysed changes in emergency physician CAP diagnosis

classification levels before and after CT scan; and their agreement with an adjudication committee. We performed univariate analysis to determine the factors associated with modifying the diagnosis classification level to be consistent with the radiologist's CT scan interpretation.

Results 319 suspected patients with CAP and 136 emergency physicians (75\% less experienced with $\leq 10$ years, $25 \%$ with $>10$ years of experience) were included. The percentage of patients whose classification was modified to become consistent with CT scan radiologist's interpretation was higher among less-experienced than experienced emergency physicians ( $54.2 \%$ vs $40.2 \%$; $p=0.02$ ). In univariate analysis, less emergency physician experience was the only factor associated with changing a classification to be consistent with the CT scan radiologist's interpretation (OR 1.77, 95\% Cl 1.01 to $3.10, p=0.04$ ). After CT scan, the agreement between emergency physicians and adjudication committee was moderate for less-experienced emergency physicians and slight for experienced emergency physicians ( $k=0.457$ and $k=0.196$, respectively). After $\mathrm{CT}$ scan, less-experienced emergency physicians modified patient management significantly more than experienced emergency physicians (36.1\% vs $21.7 \%$, $\mathrm{p}=0.01$ ).

Conclusions In clinical practice, less-experienced emergency physicians were more likely to accurately modify their CAP diagnosis and patient management based on thoracic CT scan than more experienced emergency physicians.

Trial registration number NCT01574066

\section{INTRODUCTION}

Diagnostic uncertainty is a hallmark of many emergency medicine situations. ${ }^{1}$ Community-acquired pneumonia (CAP) is one of these situations. The emergency physician must consider a set of

\section{Key messages}

What is already known on this subject

- In community-acquired pneumonia, the emergency physician must consider a set of non-specific clinical, biological and radiological data in order to make a diagnosis and care decision.

- The literature has shown that chest X-ray, the currently used radiological examination, has a poor accuracy in community-acquired pneumonia diagnosis.

- Thoracic CT scan is infrequently used in community-acquired pneumonia diagnosis in the emergency department.

- Thoracic CT scan improves community-acquired pneumonia diagnosis in patients visiting the hospital for suspected pneumonia.

- Depending on their experience, emergency physicians tend to approach medical situations differently.

What this study adds

- Thoracic CT scan results profoundly impact emergency physicians' decision-making in terms of community-acquired pneumonia diagnostic accuracy and of patients' care.

- This impact varies according to the emergency physicians' experience: less-experienced emergency physicians were more likely to appropriately reconsider their pneumonia diagnosis classification level and patient care plan than experienced emergency physicians.

- The training of emergency physicians in the adoption of a new medical technique in the care of patients should take into account emergency physicians' level of experience.

non-specific clinical, biological and radiological data in order to make a diagnostic decision. ${ }^{2} 3$ Making the right diagnosis in this situation is even more important since CAP is a frequent disease with high morbidity and mortality. ${ }^{4}$

Part of the uncertainty of CAP diagnosis may be related to the high rate of misdiagnoses based on a chest X-ray. ${ }^{56}$ We recently published a study 
in which thoracic CT scan was systematically performed after a chest X-ray in a population of clinically suspected patients with CAP visiting the emergency department (ED) (the Early thoracic CT Scan for Community-Acquired Pneumonia at the Emergency Department (ESCAPED) study). ${ }^{7}$ After CT scan, the original diagnosis based on chest X-ray was modified for many patients. These results were confirmed in another recently published study. ${ }^{8}$ The authors did not report any difference in terms of pathogens, disease severity or outcomes between patients with signs of pneumonia only on the thoracic CT scan despite normal chest X-ray and patients with signs on the chest X-ray.

The aim of this secondary analysis was to describe how radiologists' thoracic CT scan interpretations influence emergency physicians' CAP diagnosis, medical decisions and patient management. While the reference radiological examination in CAP diagnosis is today standard chest X-ray, an examination which is entrenched in CAP diagnostic pathway, thoracic CT scan appears to be much more efficient and could become the new reference examination in CAP diagnosis. ${ }^{9}{ }^{10}$ In the age of modern medicine, which constantly brings new technical advances, including radiological ones, it is necessary to question the ability of physicians to accept new techniques in their medical practice and to investigate the reasons why some physicians do not integrate the provided information into their diagnostic and therapeutic decision-making. The implementation of new diagnostic techniques only makes sense if physicians properly use them. It is, therefore, essential to identify the factors that may impact their implementation. In EDs, these factors may be related to patient characteristics, to the conditions of emergency physicians' exercise, as well as to emergency physicians' medical level of experience. ${ }^{11}$

In the present secondary analysis, we aimed to determine whether or not the emergency physician's level of experience explains why emergency physicians modified their CAP diagnosis classification level according to radiologist's CT scan interpretation and why they also modified their medical decision and their patient management.

\section{METHODS}

\section{Setting}

As previously and extensively described, 'ESCAPED' is a multicentre, prospective, interventional study. ${ }^{7}$ Data were collected from November 2011 to January 2013 in four EDs of four tertiary teaching hospitals in Paris, France, in order to assess the impact of thoracic CT scan on decision-making.

Adults (18 years of age and above) visiting the participating EDs were consecutively enrolled if the attending emergency physician clinically suspected CAP. Clinical suspicion of CAP was based on the investigator's own judgement and had to fulfil the following criteria: new onset of systemic features (at least one among: sweat, chills, aches and pain, temperature $\geq 38^{\circ} \mathrm{C}$ or $<36^{\circ} \mathrm{C}$ ) and symptoms of an acute lower respiratory tract illness (at least one among: cough, sputum production, dyspnoea, chest pain, altered breathing sounds at auscultation). To make possible, the inclusion of patients suspected of having a CAP with normal chest X-ray, patients with suspected CAP were included only on clinical criteria, before they had undergone chest X-ray. However, patients who met inclusion criteria and who had a chest X-ray before their admission to the ED were not excluded. Pregnant women, patients in palliative care or with anticipated barriers to completion of follow-up data collection, patients with a CRB65 score (Confusion, Rate of respiration $\geq 30 / \mathrm{min}$, Blood pressure: diastolic pressure $\leq 60 \mathrm{mmHg}$ or systolic pressure $<90 \mathrm{mmHg}$, 65 : age $\geq 65$ years) $\geq 3$ and those requiring intensive care for any reason due to specific management of critically ill patients with CAP, were not eligible. ${ }^{12}$

The study was sponsored and monitored by the Paris public hospital group (Assistance Publique-Hôpitaux de Paris) and funded by the French Ministry of Health.

\section{Gold standard of CAP diagnosis for the ESCAPED study}

For the ESCAPED primary study, the gold standard of CAP was the adjudication committee's final diagnosis. ${ }^{7}$ The adjudication committee consisted of three independent senior experts in infectious diseases, pneumology and radiology. They retrospectively assigned CAP probability using a four-level Likert scale. They used all baseline data, including CT scan findings (recorded on CD-ROM (Compact Disc Read Only Memory)), patients' discharge summary and follow-up data obtained by assistant investigators who phoned the patient, relatives or general practitioners on day 28. The classification of the adjudication committee makes possible, unlike the thoracic CT scan classification by the radiologist, the integration of thoracic CT scan results into all available data and provided a high level of diagnostic accuracy.

\section{Objectives}

Taking into account the emergency physicians' level of experience, the primary objective of this secondary analysis was to analyse whether or not emergency physicians modified their medical decision-making, in terms of CAP diagnosis classification level, according to thoracic CT scan interpretation by the radiologist.

The secondary objectives were: (1) to assess the patient and emergency physician characteristics that led emergency physicians to be influenced by the thoracic CT scan, (2) to assess the influence of thoracic CT scan results on patient management (modification of treatment and/or site of care) by emergency physicians, (3) to assess the accuracy of emergency physicians' pre-thoracic CT scan and post-thoracic CT scan CAP classification in relation to the adjudication committee's final diagnosis.

\section{Emergency physicians}

Emergency physicians practised in one of the four EDs involved in the ESCAPED study. For each enrolled patient, data were collected about the characteristics of the treating emergency physician (ED of work, age, gender, years of experience). Emergency physicians were categorised based on their experience in accordance with prior literature where experienced physicians were those with more than 10 years of experience in emergency medicine and less-experienced physicians were those with 10 or fewer years of experience. ${ }^{11} 1314$

\section{Patient management and data collection}

Patient management was based on local practices in the ED. Recorded baseline data consisted of demographic data (age, gender), coexisting illnesses, symptoms, clinical findings and laboratory tests.

\section{CAP diagnosis classification by emergency physicians and radiologists}

A four-level scale of CAP diagnosis (see below) was defined for each patient by emergency physicians at 2 steps of care, (1) before the thoracic CT scan, based on current examinations routinely performed by the physician (clinical examination, biological 


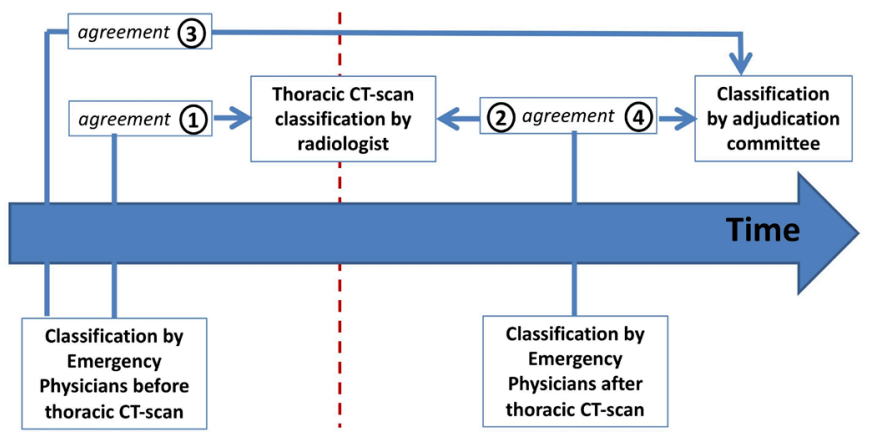

Figure 1 Level of CAP diagnosis classification: evaluation of agreement between emergency physicians classification and radiologists' classification or adjudication committee classification before and after thoracic CT scan. CAP, community-acquired pneumonia.

data, chest X-ray) and (2) after thoracic CT scan interpretation by a local radiologist, who used the same four-level scale of CAP diagnosis. The four levels of CAP diagnosis were (1) absence of CAP hereafter referred to as 'excluded CAP diagnosis', (2) 'possible CAP', (3) 'probable CAP' and (4) 'definite CAP'.

Multidetector thoracic CT scan was performed after chest $\mathrm{X}$-ray and clinical examination, ideally within 4 hours of inclusion, but patients whose CT scan had been performed more than 4 hours after inclusion were not excluded. Four levels of CAP CT scan diagnosis were defined by a local radiologist as 'definite' (systematic alveolar condensation, alveolar condensation with peripheral and localised ground glass opacities, bronchiolar focal or multifocal micronodules), 'probable' (peripheral alveolar condensation, retractile systematic alveolar condensation or diffuse ground glass opacities), 'possible' (pulmonary infarct) or 'excluded' (pulmonary mass, other abnormalities or normal images).

We considered that the thoracic CT scan interpretation modified 'positively' the emergency physicians classification in the two following situations, thereafter refer to as 'consistent modifications': first, when the modification of CAP diagnosis classification level by the emergency physician was upgraded or downgraded in the same direction as the CT scan interpretation by the radiologist. For example, a patient classified by an emergency physician as possible CAP before thoracic CT scan, classified by radiologist as probable CAP, and then classified by emergency physician as definite CAP, was considered as upgraded in the same direction as the CT scan interpretation (online supplementary appendix 1); second, the CAP diagnosis classification level was not modified by the emergency physician after the CT scan but was identical to the radiologist's interpretation.

We also considered that the thoracic CT scan interpretation modified 'negatively' the emergency physicians' classification, when the modification of CAP diagnosis level by the emergency physicians led them to become more discordant with the radiologist's interpretation.

Finally, the CAP classification by the emergency physician was considered 'in agreement' with the CT scan radiologist's interpretation (or the adjudication committee classification), when the two classifications were strictly identical, thereafter referred to as in agreement.

\section{Statistical analysis}

Baseline and follow-up characteristics of the total study population were described by means, standard deviation (SD) and (minimum; maximum); and by percentages for categorical variables. $\mathrm{X}^{2}$ or Fisher's exact tests were performed when appropriate for categorical variables and the Student or Mann-Whitney $\mathrm{U}$ tests for continuous variables, kappa statistic was used to test inter-rater agreement.

To determine whether or not emergency physicians modified their medical decision-making according to thoracic CT scan interpretation by the radiologist, we carried out an analysis in several steps (figure 1). We first determined the number of pre-CT diagnoses that were in agreement with the radiologist's CT scan interpretation for all physicians and for the more and less-experienced physicians separately (step 1 ). We also determined the number of post-CT diagnoses that were in agreement with the radiologists' CT scan interpretation (step 2). To assess our secondary objective, we determined the number of patients classified in agreement with the adjudication committee classification, before (step 3) and after (step 4) thoracic CT scan, by emergency physicians. These data made it possible to ensure that the number of patients 'accurately classified' was not different before CT scan between experienced and less-experienced emergency physicians and to assess whether the classification changes were accurately carried out (figure 1 ).

To assess the influence of thoracic CT scan interpretation by radiologist on CAP diagnosis classification level by emergency physicians, according to their experience, we compared the proportion of patients whose classification was modified to become consistent or to become more discordant with the thoracic CT scan interpretation, according to emergency physicians' experience.

A univariate logistic regression analysis was performed to identify characteristics of patients and practitioners for whom emergency physician CAP diagnosis classification level was 'consistent with the CT scan interpretation by the radiologist'. The choice of variables for univariate analysis was pragmatic and included emergency physician characteristics and patient characteristics (age, chronic respiratory diseases or previous antibiotic therapy). The conduct of a multivariate analysis was conditioned on the identification of at least two variables with a $p<0.20$ in univariate analysis and the absence of colinearity between the variables identified.

All tests were two sided, and $\mathrm{p}$ values below 0.05 were considered to denote statistical significance. All statistical analyses were performed using R software V.3.3.3 (R Foundation, Auckland, New Zealand).

\section{RESULTS}

One hundred and thirty-six emergency physicians enrolled at least one patient in the ESCAPED study. Characteristics of the 136 emergency physicians (age, gender, years of experience, $\mathrm{ED}$, number of patients enrolled) are summarised in table 1. A quarter $(25.0 \%)$ of the emergency physicians had more than 10 years of professional experience and were therefore considered as 'experienced'. Less-experienced emergency physicians enrolled 227 (71.2\%) of the 319 patients and experienced emergency physicians enrolled $92(28.8 \%)$ patients (table 1$)$.

Characteristics of the 319 patients, according to the level of experience of the emergency physicians are summarised in table 2. More than half of the patients $(55.5 \%)$ were 65 years of age or older. At inclusion, there was no difference between the characteristics of patients included by the less-experienced emergency physicians and those included by the experienced emergency physicians. Eight patients had undergone chest X-ray before their arrival in the ED. 


\begin{tabular}{|c|c|}
\hline \multirow[b]{2}{*}{ Characteristics } & \multirow{2}{*}{$\begin{array}{l}\text { No }(\%) \text { or mean } \pm \text { SD } \\
\text { Total }(n=136)\end{array}$} \\
\hline & \\
\hline \multicolumn{2}{|l|}{ General characteristics } \\
\hline \multicolumn{2}{|l|}{ Age } \\
\hline Mean age (years) & $37.0 \pm 8.6$ \\
\hline \multicolumn{2}{|l|}{ Sex } \\
\hline Female & $66(48.5)$ \\
\hline Male & $70(51.5)$ \\
\hline \multicolumn{2}{|l|}{ Emergency activity } \\
\hline \multicolumn{2}{|l|}{ Emergency department } \\
\hline Bichat-Claude Bernard University Hospital & $35(25.7)$ \\
\hline Cochin University Hospital & $45(33.1)$ \\
\hline La Pitié-Salpétrière University Hospital & $39(28.7)$ \\
\hline Tenon University Hospital & $17(12.5)$ \\
\hline \multicolumn{2}{|l|}{ Emergency experience } \\
\hline Years of experience & $6.5 \pm 6.3$ \\
\hline Years of experience $>10$ years & $34(25.0)$ \\
\hline \multicolumn{2}{|l|}{ Enrolment in the ESCAPED study } \\
\hline Patients enrolled & $2.3 \pm 2.2$ \\
\hline
\end{tabular}

Results are expressed as number (\%) or mean \pm SD.

ESCAPED, Early thoracic CT Scan for Community-Acquired Pneumonia at the Emergency Department.

\section{Agreement between CAP diagnosis classification level by} emergency physicians and radiologist CT scan interpretation according to emergency physicians experience

Table 3 displays the emergency physicians' levels of CAP diagnosis classification before and after the thoracic CT scan. Before thoracic CT scan, emergency physicians classified 110 of the 319 patients $(34.5 \%)$ a posteriori in agreement with the radiologist's interpretation (table 3 and figure 2); the agreements between emergency physicians and radiologist were slight for either less-experienced emergency physicians $(\mathrm{k}=0.094,95 \% \mathrm{CI}$ 0.031 to 0.156$)$ or experienced emergency physicians $(\mathrm{k}=0.153$, $95 \%$ CI 0.041 to 0.264$)$. After the thoracic CT scan, emergency physicians classified 220 patients $(68.9 \%)$ patients in agreement with the radiologist's interpretation; the agreements between emergency physicians and radiologist was moderate for less-experienced emergency physicians $(\mathrm{k}=0.589,95 \%$ CI 0.508 to
$0.669)$ and fair for experienced emergency physicians $(\mathrm{k}=0.390$, $95 \%$ CI 0.260 to 0.519 ) (table 3 and online supplementary appendices 2 and 3 ).

Influence of thoracic CT scan interpretation by radiologist on CAP diagnosis classification level by emergency physicians, according to their experience

The proportion of patients whose classification was modified to become consistent with the thoracic CT scan results was significantly higher among those treated by less-experienced emergency physicians than by experienced emergency physicians (123 $(54.2 \%)$ of 227 patients vs $37(40.2 \%)$ of 92 patients, respectively) $(\mathrm{p}=0.02)$. The proportion of patients whose classification was modified to become more discordant with the CT scan radiologist's interpretation was not significantly different between patients treated by less-experienced emergency physicians and those treated by experienced emergency physicians $(18$ $(7.9 \%)$ of 227 patients vs $10(10.8 \%)$ of 92 patients, respectively) $(\mathrm{p}=0.40)$ (figure 2).

\section{Patient and emergency physician characteristics associated with CAP diagnosis classification level by emergency physician consistent with the $\mathrm{CT}$ scan interpretation by the radiologist}

Determinants for an emergency physician to be consistent with the radiologist's CT scan interpretation are summarised in table 4. In univariate analysis, being a less-experienced emergency physician was the only variable of statistical significance $(p<0.05)$ for reclassifying CAP diagnosis in concordance with $\mathrm{CT}$ scan interpretation. As the two variables identified in univariate analysis with a $\mathrm{p}<0.20$ (age and experience of emergency physicians) were colinear $(\mathrm{p}<0.01)$, the multivariate analysis was not conducted.

\section{Influence of the thoracic CT scan results on patient management by emergency physicians}

After obtaining the thoracic CT scan results, less-experienced emergency physicians more frequently modified their treatment (stopping or initiating antibiotic therapy) and/or their decision for the site-of-care (admission or discharge) than experienced emergency physicians $(82(36.1 \%)$ out of 227 patients vs 20 $(21.7 \%)$ out of 92 patients, respectively) $(\mathrm{p}=0.01)$.

Table 2 Characteristics of the 319 patients of the study according to the level of experience of the Emergency Physicians

\begin{tabular}{|c|c|c|c|c|}
\hline \multirow[b]{2}{*}{ Patients characteristics } & No $(\%)$ or mean \pm SD & \multirow{2}{*}{$\begin{array}{l}\text { Emergency Physicians } \\
\leq 10 \text { years of experience } n=227\end{array}$} & \multirow{2}{*}{$\begin{array}{l}\text { Emergency Physicians } \\
>10 \text { years of experience } n=92\end{array}$} & \multirow[b]{2}{*}{$P$ value } \\
\hline & Total $(n=319)$ & & & \\
\hline \multicolumn{5}{|l|}{ General characteristics } \\
\hline \multicolumn{5}{|l|}{ Age } \\
\hline Mean age (years) & $64.7 \pm 20.0$ & $64.5 \pm 19.9$ & $65.1 \pm 20.4$ & 0.82 \\
\hline$\geq 65$ years & $177(55.5)$ & $125(55.1)$ & $52(56.5)$ & 0.81 \\
\hline \multicolumn{5}{|l|}{ Gender } \\
\hline Female & $164(51.4)$ & $118(52.0)$ & $46(50.0)$ & 0.80 \\
\hline Male & $155(48.6)$ & $109(48.0)$ & $46(50.0)$ & \\
\hline \multicolumn{5}{|l|}{ Comorbidities } \\
\hline Chronic respiratory disease & 89 (27.9) & $64(28.2)$ & $25(27.2)$ & 0.28 \\
\hline \multicolumn{5}{|c|}{$\begin{array}{l}\text { Community-acquired pneumonia characteristics at } \\
\text { inclusion }\end{array}$} \\
\hline Previous antibiotic treatment & $111(34.8)$ & 79 (34.8) & $32(34.8)$ & 1.00 \\
\hline
\end{tabular}

Results are expressed as number (\%) or mean \pm SD.

$S D$, standard deviation. 
Table 3 Agreement between EPs and radiologist CT scan interpretation and between EPs and adjudication committee for CAP diagnosis classification level, according to EPs experience

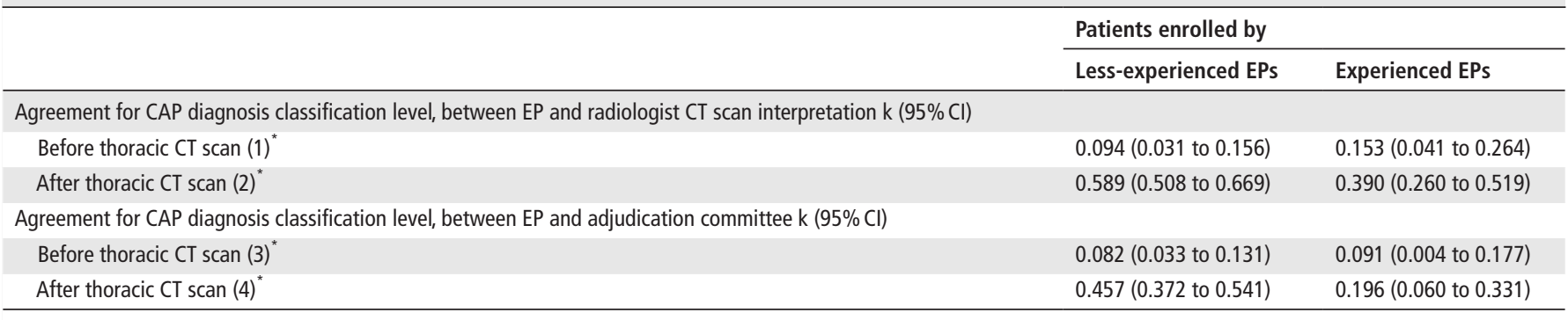

${ }^{*}$ References to figure 1 .

EP, emergency physician.

\section{Agreement between the emergency physicians' CAP diagnosis classification level and the adjudication committee CAP diagnosis classification level}

Before thoracic CT scan, the agreements between emergency physicians and the adjudication committee were slight for either less-experienced emergency physicians $(\mathrm{k}=0.082,95 \%$ CI 0.033 to 0.131$)$ or experienced emergency physicians $(\mathrm{k}=0.091$, $95 \%$ CI 0.004 to 0.177 ). (table 3 ).

After the thoracic CT scan, the agreement between emergency physicians and the adjudication committee was moderate for less-experienced emergency physicians $(k=0.457,95 \% \mathrm{CI}$ 0.372 to 0.541 ) and slight for experienced emergency physicians $(\mathrm{k}=0.196,95 \% \mathrm{CI} 0.060$ to 0.331$)$ (online supplementary appendix 4) (table 3). The adjudication committee was in strict agreement with the radiologist classification for 210 patients (online supplementary appendix 5).

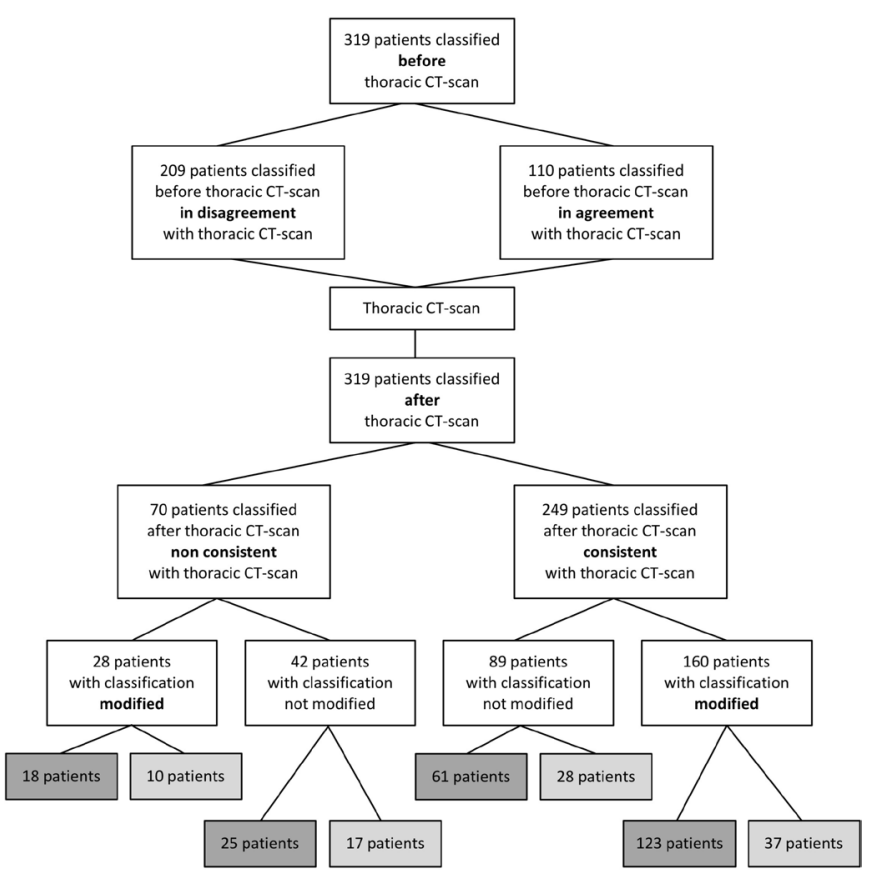

Patients classified by less-experienced Emergency Physicians Patients classified by experienced Emergency Physicians

Figure 2 Patients classification before and after thoracic CT scan according to CT scan interpretation by radiologist.

\section{DISCUSSION}

In this study, we explored medical decision-making in a situation in which emergency physicians are provided with additional and not routinely available information in an actual emergency medicine setting. We showed that the majority of emergency physicians were influenced by the radiologist's CT scan interpretation. Professional experience of 10 or fewer years was associated with a greater likelihood of the physicians' changing their diagnostic certainty to be concordant with the radiologist's interpretation of the thoracic CT scan. The higher rate of modification of less-experienced emergency physicians was not due to a 'worse' pre-CT scan classification than the experienced emergency physicians. When comparing emergency physicians classification established after thoracic CT scan to the adjudication committee classification, less-experienced emergency physicians were more in line with the adjudication committee than experienced emergency physicians.

The patient clinical characteristics (age and comorbidities) included in this study are consistent with those of patients included in previous studies analysing patients with CAP. ${ }^{15} 16$ The emergency physicians, all practised in one of four tertiary teaching hospital EDs in Paris. However, having been trained in different French universities, they can be considered representative of French emergency physicians.

The impact of CT scans on diagnostic accuracy and decision-making is consistent with the emergency medicine ${ }^{17} 18$ and primary care literature, ${ }^{19}$ showing a frequent change in diagnosis after CT scan. Our study suggests that this impact is also observed in situations where CT scans are not routinely used for diagnosis. We also showed that the likelihood of changing the diagnosis is associated with the length of emergency physicians' experience in practice. In contrast with data from Schubert et al publication, less-experienced emergency physicians were more flexible and more willing to change their initial assessment when confronted with further data, in our case, the results of the CT scan. ${ }^{11}$ Indeed, in this publication focusing on ED practice, novice physicians tended to rely on objective data more frequently than experienced emergency physicians; however, they prematurely closed their assessments, discounting data that did not fit their framing. On the contrary, experienced emergency physicians tended to maintain a broader picture of the situation, were more sensitive to deviations from their expectations, and were more willing to change their initial assessments. ${ }^{11}$

This stronger propensity to change among less-experienced emergency physicians was not due to a higher wrong classification before the results of CT scan as compared with experienced emergency physicians. The changes were appropriate as they were 
Table 4 Univariate analysis of physician and patient characteristics associated with CAP diagnosis classification level consistent with the CT scan interpretation by the radiologist

\begin{tabular}{|c|c|c|c|c|}
\hline Characteristics n (\%) or mean (SD) & $\begin{array}{l}\text { Total } \\
n=319\end{array}$ & $\begin{array}{l}\text { Classification consistent with } \\
\text { thoracic CT scan interpretation } \\
\mathrm{n}=249\end{array}$ & $\begin{array}{l}\text { Classification } \\
\text { non-consistent with thoracic } \\
\text { CT scan interpretation } \\
\mathrm{n}=70\end{array}$ & $\begin{array}{l}\text { Univariate analysis } \\
\text { OR } \\
(95 \% \mathrm{Cl}) \mathrm{p} \text { value* }\end{array}$ \\
\hline \multicolumn{5}{|l|}{ Physician characteristics } \\
\hline $\begin{array}{l}\text { Physician age (years) } \\
\text { Mean (SD) } \\
\text { (min; max) }\end{array}$ & $\begin{array}{l}37.03(8.65) \\
(24 ; 60)\end{array}$ & $\begin{array}{l}37.87(8.87) \\
(24 ; 60)\end{array}$ & $\begin{array}{l}39.60(10.03) \\
(25 ; 60)\end{array}$ & $\begin{array}{l}1.02 \\
(0.99 \text { to } 1.04) \\
0.163\end{array}$ \\
\hline $\begin{array}{l}\text { Physician gender } \\
\text { Male } \mathrm{n}(\%) \\
\text { Female } \mathrm{n}(\%)\end{array}$ & $\begin{array}{l}144(45.0) \\
175(55.0)\end{array}$ & $\begin{array}{l}110(44.2) \\
139(55.8)\end{array}$ & $\begin{array}{l}34(48.6) \\
36(51.4)\end{array}$ & $\begin{array}{l}1.19 \\
(0.70 \text { to } 2.03) \\
0.514\end{array}$ \\
\hline \multicolumn{5}{|l|}{ Physician experience } \\
\hline $\begin{array}{l}\leq 10 \text { years } \mathrm{n}(\%) \\
>10 \text { years } \mathrm{n}(\%)\end{array}$ & $\begin{array}{l}227(71.2) \\
92(28.8)\end{array}$ & $\begin{array}{l}184(73.9) \\
65(26.1)\end{array}$ & $\begin{array}{l}43(61.4) \\
27(38.6)\end{array}$ & $\begin{array}{l}1.77 \\
(1.01 \text { to } 3.10) \\
0.043\end{array}$ \\
\hline \multicolumn{5}{|l|}{ Patient characteristics } \\
\hline $\begin{array}{l}\text { Patient age } \\
\text { Mean (SD) } \\
\text { (min; max) }\end{array}$ & $\begin{array}{l}64.75(20.02) \\
(18 ; 100)\end{array}$ & $\begin{array}{l}64.50(19.81) \\
(18 ; 100)\end{array}$ & $\begin{array}{l}65.41(20.88) \\
(19 ; 96)\end{array}$ & $\begin{array}{l}1.00 \\
(0.98 \text { to } 1.01) \\
0.736\end{array}$ \\
\hline \multicolumn{5}{|l|}{ Chronic respiratory disease $†$} \\
\hline $\begin{array}{l}\text { Yes, n (\%) } \\
\text { No, n (\%) }\end{array}$ & $\begin{array}{l}89(28.2) \\
229(71.8)\end{array}$ & $\begin{array}{l}70(28.5) \\
178(71.5)\end{array}$ & $\begin{array}{l}19(27.1) \\
51(72.9)\end{array}$ & $\begin{array}{l}1.05 \\
(0.58 \text { to } 1.91) \\
0.908\end{array}$ \\
\hline \multicolumn{5}{|l|}{ Previous antibiotic treatment } \\
\hline $\begin{array}{l}\text { Yes, n (\%) } \\
\text { No, n (\%) }\end{array}$ & $\begin{array}{l}111(34.8) \\
208(65.2)\end{array}$ & $\begin{array}{l}83(33.3) \\
166(66.7)\end{array}$ & $\begin{array}{l}28(40.0) \\
42(60.0)\end{array}$ & $\begin{array}{l}0.75 \\
(0.43 \text { to } 1.29) \\
0.302\end{array}$ \\
\hline \multicolumn{5}{|l|}{ Classification before thoracic CT scan } \\
\hline Excluded & $4(1.3)$ & $4(1.5)$ & $0(0)$ & \multirow{4}{*}{$\begin{array}{l}0.96 \\
(0.68 \text { to } 1.35) \\
0.832\end{array}$} \\
\hline Possible & $53(16.6)$ & $38(15.3)$ & $15(21.4)$ & \\
\hline Probable & $118(37.0)$ & $95(38.2)$ & $23(32.9)$ & \\
\hline Definite & $144(45.1)$ & $112(45.0)$ & $32(45.7)$ & \\
\hline
\end{tabular}

* $P$ value from Wald test (logistic regression).

t(One missing data).

CAP, community-acquired pneumonia.

more in line with the adjudication committee. Furthermore, these changes were not only theoretical as they translated into changes in patients' care, such as the modification of the site of care and antibiotic initiation or cessation.

Several hypotheses can be put forward in regard to this willingness to change diagnoses. First, less-experienced emergency physicians may be more influenced by a radiologist's CT scan interpretation. This suggests the impact of senior advice on young practitioners' decisions. Recent studies in the field of emergency medicine have indeed shown that expert physicians interpret data according to the confidence they have in the deliverer of data (ie, other health professionals). ${ }^{20}$ Our study suggests that this may also be the case with less-experienced physicians as they are more likely to have confidence in a senior physician or a specialist in radiology. Second, these data were collected in the context of a clinical trial evaluating the added value of a thoracic CT scan, which was not yet validated for this condition. This suggests that when data are collected from non-recommended examinations, experienced physicians are less inclined to modify their practice. For 28 patients, emergency physicians consciously changed their level of CAP diagnosis classification to diverge from the radiologist's interpretation. We can hypothesise that these emergency physicians were waiting for the results of the trial before modifying their practice. Finally, less-experienced emergency physicians may be both more likely to believe in new medical imaging than experienced emergency physicians and more comfortable with the use of CT scans, especially as CT scan interpretation is part of their initial training. ${ }^{21}$

This study has some limitations. First, we have little information on emergency physician characteristics. In addition to age and experience, it might have been useful to rank their radiology skills and medical training. Second, the choice of the cut-off at 10 years to define expertise may be called into question. While not consensual, it has been acknowledged that individuals need a minimum of 10 years of medical practice to gain expertise. ${ }^{13} 14$ Third, if a physician did not modify his classification, with classifications before and after CT scan identical to the radiologist's, it was considered to be consistent. However, in a sensitivity analysis excluding these patients, we found similar results. Fourth, one can also wonder to what extent the will to not take into account the results of the thoracic CT scan could subsequently translate into the will not to have asked for a thoracic CT scan for such a patient. It has indeed been reported that less-experienced physicians are more likely to use imaging, partly because they have less confidence in their diagnosis. ${ }^{22}$ Finally, agreement between emergency physicians and radiologists CT scan interpretation or between emergency physicians and the adjudication committee were moderate at best. This may be explained by the different situations at the time of decision-making. In contrast to emergency physicians, the radiologist's 
diagnosis was only based on CT scan images; regarding the adjudication committee, who had all the data collected, between the emergency visit and the follow-up up to day 28 including CT scan images which placed him in a more favourable position to make an accurate diagnosis.

In summary, in our population of emergency physicians caring for patients with a clinical suspicion of CAP, being informed of thoracic CT scan results had a significant impact on their medical decision in terms of diagnostic certainty. The radiologist's CT scan interpretation was taken into account by emergency physicians for nearly three-quarters of the patients. While their diagnostic classifications were slight in both group before the CT scan, less-experienced emergency physicians were more willing to change their initial impression in comparison with experienced emergency physicians. Contrary to what was expected based on the literature, this study assessing medical decision in an authentic setting ${ }^{23}$ showed that less-experienced emergency physicians modified their initial diagnosis more easily than experienced emergency physicians and accurately so. These data should be assessed outside the context of a clinical trial evaluating the performance of a new imaging technique. Furthermore, the level of experience of emergency physicians could be taken into account in training in the adoption of new medical techniques for patient care.

\section{Author affiliations}

${ }^{1}$ Department of General Practice, Universite Paris Diderot UFR de Medecine Site Xavier-Bichat, Paris, France

¿UMR 1137, IAME, INSERM, Paris, France

${ }^{3}$ Faculty of Medicine, Centre for Training and Research in Health Sciences Education (CFR-PS), University of Strasbourg, Strasbourg, France

${ }^{4}$ Prehospital Emergency Care Service (SAMU 67), Hopitaux Universitaires de Strasbourg, Strasbourg, France

DDepartment of Emergency Medicine and Surgery, Hôpital Tenon, Assistance Publique-Hôpitaux de Paris (APHP), Paris, France

${ }^{6}$ Department of Respiratory Diseases, Hôpital Tenon, Assistance Publique-Hôpitaux de Paris (APHP), Paris, France

${ }^{7}$ Department of Radiodiagnosis, Groupe Hospitalier Pitié-Salpêtrière Charles Foix, Assistance Publique-Hôpitaux de Paris (APHP), Paris, France

${ }^{8}$ GRC-14 BIOSFAST Qet APHP, Sorbonne Université UPMC-Univ Paris 06, Paris, France ${ }^{9}$ Emergency Department, Hôpital Bichat-Claude Bernard, Assistance PubliqueHôpitaux de Paris (APHP), Paris, France

${ }^{10}$ Emergency Medicine, Centre Hospitalier Princesse Grace, Monaco, Europe ${ }^{11} \mathrm{CIC}$ 1425, Hôpital Bichat-Claude Bernard, Assistance Publique-Hôpitaux de Paris (APHP), Paris, France

Acknowledgements Scientific committee-Steering committee: Y-EC, (principal investigator), XD (coprincipal investigator), E. Bouvard; MF Carette); MP Debray; CM; C. Leport; N Houhou; S Tubiana. Validation committee: MB, X. Blanc, A-LB, L Epelboin, C Ficko, A Khalil, H Lefloch, JM Naccache, B Rammaert. Clinical investigators: A Abry, JC Allo, S Andre, C Andreotti, N Baarir, M Bendahou, L Benlafia, J Bernard, A Berthoumieu, ME Billemont, J Bokobza, A-LB, E Burggraff, P Canavaggio, MF Carette, EC, S Castro, C Choquet, H Clément, L Colosi, A Dabreteau, S

Damelincourt, S Dautheville, MP Debray, M Delay, S Delerme, L Depierre, F Djamouri, F Dumas, MRS Fadel, A Feydey, Y Freund, L Garcia, H Goulet, PH, E llic-Habensus, MO Josse, J Kansao, Y Kieffer, F Lecomte, K Lemkarane, P Madonna, O Meyniard, L Mzabi, D Pariente, J Perne, F Perruche, JM Piquet, R Ranerison, PR, F Renai, E Rouff, D Saget, K Saïdi, G Sauvin, E Trabattoni, N Trimech. Monitoring, data management and statistical analysis: C Auger, C Laouénan, B Pasquet, S Tamazirt, JM Treluyer, F Tubach, S Tubiana, J Wang. Sponsor: Assistance Publique-Hôpitaux de Paris, Délégation Interrégionale à la Recherche Clinique d'lle De France, O Chassany, C Misse.

Collaborators Scientific committee - Steering committee Y.E. Claessens, (MD PhD, principal investigator), X. Duval (MD PhD, co-principal investigator), E. Bouvard (MD); M.F. Carette (MD PhD); M.P. Debray (MD PhD); C. Mayaud (MD PhD); C. Leport (MD PhD); N. Houhou (MD PhD); S. Tubiana (PhD). Validation committee: M. Benjoar (MD), X. Blanc (MD PhD), A.L Brun (MD), L. Epelboin (MD), C. Ficko (MD), A. Khalil (MD PhD), H. Lefloch (MD), JM. Naccache (MD PhD), B. Rammaert (MD PhD). Clinical investigators: A. Abry (MD), J.C. Allo (MD), S. Andre (MD), C. Andreotti (MD), N. Baarir (MD), M. Bendahou (MD), L. Benlafia (MD), J. Bernard (MD), A. Berthoumieu (MD), M.E. Billemont (MD), J. Bokobza (MD), A.L. Brun (MD), E. Burggraff (MD), P. Canavaggio (MD), M.F. Carette (MD PhD), E. Casalino (MD PhD), S. Castro (MD), C. Choquet (MD), H. Clément (MD), L. Colosi (MD), A. Dabreteau (MD), S. Damelincourt
(MD), S. Dautheville (MD), M.P. Debray (MD), M. Delay (MD), S. Delerme (MD), L. Depierre (MD), F. Djamouri (MD), F. Dumas (MD), M.R.S. Fadel (MD), A. Feydey (MD), Y. Freund (MD), L. Garcia (MD), H. Goulet (MD), P. Hausfater (MD PhD), E. llic Habensus (MD), M.O. Josse (MD), J. Kansao (MD), Y. Kieffer (MD), F. Lecomte (MD), K. Lemkarane (MD), P. Madonna (MD), O. Meyniard (MD), L. Mzabi (MD), D. Pariente (MD), J. Pernet (MD), F. Perruche (MD), J.M. Piquet (MD), R. Ranerison (MD), P. Ray (MD PhD), F. Renai (MD), E. Rouff (MD), D. Saget (MD), K. Saïdi (MD), G. Sauvin (MD), E. Trabattoni (MD), N. Trimech (MD).

Contributors Conception and design: Y-EC and XD designed the ESCAPED study. Acquisition of data: PR, CM, A-LB, PH, EC, MB and Y-EC obtained clinical and radiological data. Analysis and interpretation of data: JLB, TP, XD and Y-EC analysed data. Drafting of the manuscript: JLB, TP, XD and Y-EC were responsible for the manuscript draft. Critical revision of the manuscript for important intellectual content: PH, PR and CM provided critical review. Each author read the manuscript and provided criticisms that were included in the manuscript. All the authors finally accept the revised manuscript. Statistical analysis: JLB was responsible for the statistical analysis. Obtaining funding: Y-EC and XD obtained institutional funding. Al authors have participated sufficiently in the work to take public responsibility for the whole content of the manuscript. Other peoples who contributed significantly to the work are listed in the acknowledgements.

Funding Financial support for this study was provided entirely by a research grant from the French Ministry of Health (PHRC AOM 10014). The funding agreement ensured the authors' independence in designing the study, interpreting the data, writing and publishing the report

Competing interests JLB reports grants from Pfizer, outside the submitted work. Y-EC reports grants from the French Ministry of Health, during the conduct of the study, and reports grants from Biomerieux, Sanofi and Bayer, outside the submitted work. XD reports grants from the French Ministry of Health, during the conduct of the study, and reports grants from Pfizer, outside the submitted work.

\section{Patient consent for publication Not required.}

Ethics approval The French health authorities (The French National Agency for Medicines and Health Products, ANSM) and the institutional review board for the protection of human subjects approved the study protocol. The Ethics Committee of lle de France (Comité de Protection des Personnes. Paris no 2011-Oct-12749) approved the study protocol.

Provenance and peer review Not commissioned; externally peer reviewed.

Open access This is an open access article distributed in accordance with the Creative Commons Attribution Non Commercial (CC BY-NC 4.0) license, which permits others to distribute, remix, adapt, build upon this work non-commercially, and license their derivative works on different terms, provided the original work is properly cited, appropriate credit is given, any changes made indicated, and the use is non-commercial. See: http://creativecommons.org/licenses/by-nc/4.0/.

\section{REFERENCES}

1 Croskerry P. Critical thinking and decisionmaking: avoiding the perils of thin-slicing. Ann Emerg Med 2006;48:720-2.

2 Gennis P, Gallagher J, Falvo C, et al. Clinical criteria for the detection of pneumonia in adults: guidelines for ordering chest roentgenograms in the emergency department. $J$ Emerg Med 1989;7:263-8.

3 Metlay JP, Fine MJ. Testing strategies in the initial management of patients with community-acquired pneumonia. Ann Intern Med 2003;138:109-18.

4 Mandell LA. Epidemiology and etiology of community-acquired pneumonia. Infect Dis Clin North Am 2004:18:761-76.

5 Albaum MN, Hill LC, Murphy M, et al. Interobserver reliability of the chest radiograph in community-acquired pneumonia. PORT Investigators. Chest 1996;110:343-50.

6 Hopstaken RM, Witbraad T, van Engelshoven JM, et al. Inter-observer variation in the interpretation of chest radiographs for pneumonia in community-acquired lower respiratory tract infections. Clin Radiol 2004;59:743-52.

7 Claessens YE, Debray MP, Tubach F, et al. Early chest computed tomography scan to assist diagnosis and guide treatment decision for suspected community-acquired pneumonia. Am J Respir Crit Care Med 2015;192:974-82.

8 Upchurch CP, Grijalva CG, Wunderink RG, et al. Community-acquired pneumonia visualized on CT scans but not chest radiographs: pathogens, severity, and clinica outcomes. Chest 2018;153:601-10

9 Prendki V, Scheffler M, Huttner B, et al. Low-dose computed tomography for the diagnosis of pneumonia in elderly patients: a prospective, interventional cohort study. Eur Respir J 2018:51:1702375.

10 Self WH, Courtney DM, McNaughton CD, et al. High discordance of chest x-ray and computed tomography for detection of pulmonary opacities in ED patients: implications for diagnosing pneumonia. Am J Emerg Med 2013;31:401-5.

11 Schubert CC, Denmark TK, Crandall B, et al. Characterizing novice-expert differences in macrocognition: an exploratory study of cognitive work in the emergency department. Ann Emerg Med 2013;61:96-109. 


\section{Original article}

12 Bauer TT, Ewig S, Marre R, et al. CRB-65 predicts death from community-acquired pneumonia. J Intern Med 2006;260:93-101.

13 Ericsson KA. Deliberate practice and the acquisition and maintenance of expert performance in medicine and related domains. Acad Med 2004;79(10 Suppl):S70-81.

14 Croskerry P, Sinclair D. Emergency medicine: a practice prone to error? CJEM 2001;3:271-6.

15 Metlay JP, Schulz R, Li YH, et al. Influence of age on symptoms at presentation in patients with community-acquired pneumonia. Arch Intern Med 1997;157:1453-9.

16 Fine MJ, Auble TE, Yealy DM, et al. A prediction rule to identify low-risk patients with community-acquired pneumonia. N Eng/ J Med 1997;336:243-50.

17 Abujudeh HH, Kaewlai R, McMahon PM, et al. Abdominopelvic CT increases diagnostic certainty and guides management decisions: a prospective investigation of 584 patients in a large academic medical center. AJR Am J Roentgenol 2011;196:238-43.
18 Pandharipande PV, Reisner AT, Binder WD, et al. CT in the emergency department: a realtime study of changes in physician decision making. Radiology 2016;278:812-21.

19 Pandharipande PV, Alabre Cl, Coy DL, et al. Changes in physician decision making after CT: a prospective multicenter study in primary care settings. Radiology 2016;281:835-46.

20 Pelaccia T, Tardif J, Triby E, et al. From context comes expertise: how do expert emergency physicians use their know-who to make decisions? Ann Emerg Med 2016:67:747-51

21 Halm EA, Atlas SJ, Borowsky LH, et al. Understanding physician adherence with a pneumonia practice guideline: effects of patient, system, and physician factors. Arch Intern Med 2000;160:98-104.

22 Baloescu C. Diagnostic imaging in emergency medicine: how much is too much? Ann Emerg Med 2018;72:637-43.

23 Blumenthal-Barby JS, Krieger H. Cognitive biases and heuristics in medical decision making: a critical review using a systematic search strategy. Med Decis Making 2015;35:539-57. 